\title{
Changes in Recruitment of Motor Cortex Excitation and Inhibition in Patients with Drug Induced Tardive Syndromes
}

Eman M Khedr ${ }^{{ }_{1} 1}(\mathrm{MD})$, Bastawy Al Fawal ${ }^{2}(\mathrm{MD})$, Ahmed M Abdelwarith ${ }^{2}$ (MD), Mostafa Saber ${ }^{2}$ (MD), Abeer Abdel hady Tony (MD)², Ahmed ElBassiony (MD) ${ }^{3}$, and John C Rothwell ${ }^{4}(\mathrm{PHD})$

${ }^{1}$ Department of Neuropsychiatry, Faculty of Medicine, Assiut University, Assuit, Egypt and the Academic director of Neuropsychiatry Department, Faculty of Medicine Aswan University Aswan/Egypt

2Department of Neuropsychiatry, Faculty of Medicine, Aswan University, Aswan, Egypt.

${ }^{3}$ Department of Neuropsychiatry, Faculty of Medicine, Ain shams University, Cairo/ Egypt.

${ }^{4}$ Sobell Department of Motor Neuroscience and movement Disorders, National Hospital for Neurology and Neurosurgery, Queen Square, London, UK

Running title: cortical excitability of drug induced tardive dyskinesia

Key Words: , Contralateral cortical silent period, cortical excitability; drug

induced extrapyramidal, Input-output curve, motor threshold, Tardive

dyskinesia, Tardive syndrome, transcranial magnetic stimulation; ,

transcallosal inhibition

\section{*Corresponding Author}

Prof. Dr. Eman M. Khedr

Head of Department of Neuropsychiatry, Faculty of Medicine

Assiut University Hospital, Assiut, Egypt

Director of the Neuropsychiatric Department,

Faculty of Medicine, Aswan University Hospital

Phone: +02-01005850632

Fax: +02-088-2333327

Email: emankhedr99@yahoo.com

Number of words in the abstract 200

Text words 2412

Number of figure $=2$

Number of tables $=3$

Number of references $=25$ 


\section{Abstract}

Objectives: It has recently been suggested that drug induced Tardive Syndromes (TS) might be due to maladaptive plasticity which increases motor excitability in cerebral cortex and basal ganglia. In order to test this hypothesis we performed the first measurements of cortical excitability in TS.

Methods: Motor cortex excitability was examined using transcranial magnetic stimulation (TMS) in 22 TS patients and compared with that in 20 age and sex-matched healthy individuals. Resting and active motor threshold (RMT, AMT) and input-output curves (I/O curves) assessed corticospinal excitability. The duration of the contralateral silent period (cSP) at a range of stimulation intensities and ipsilateral silent period (iSP) were used as measures of inhibition.

Results: There were no significant differences in RMT and AMT between patients and controls, although the input-output curves were significantly steeper in patients. The cSP (at different stimulus intensities) and iSP were both longer in the patients compared to the control group. But most of this difference could be accounted for by increased recruitment of motor evoked potentials (MEPs) in patients.

Conclusion: TS is characterized by hyperexcitability of corticospinal output that might contribute to the lack of selectivity in muscle recruitment and contribute to excess involuntary movement. The findings are opposite to those in naturally-occurring hyperkinesia such as Sydenham's and Huntington's chorea suggesting a fundamental difference in the pathophysiology.

\section{Introduction}

Tardive syndrome (TS) is defined as a group of disorders caused by exposure to a dopamine receptor antagonist within 6 months of the onset of symptoms and persisting for at least 1 month after stopping the offending drug [6]. The occurrence of TD is estimated to be $2 \%-5 \%$ annually, ${ }^{16-18}$ and the condition occurs in $15 \%-30 \%$ of those who receive long-term treatment with APDs. The occurrence of TD can also depend on whether the APD is typical (also known 
as first generation) or atypical (also known as second generation), 18 with a $32.4 \%$ occurrence with typical APDs and a $13.1 \%$ occurrence with atypical APDs.19. According to the diagnostic and statistical manual of mental disorders, $5^{\text {th }}$ edition (DSM V) [1], the spectrum of TS includes involuntary movements of the tongue, jaw, trunk, or extremities, and may be choreiform, athetoid, or stereotypic in nature. Based on the phenomenology, tardive syndromes can be subtyped as: tardive dyskinesia, tardive stereotypy, tardive dystonia, tardive tremor, tardive akathisia, tardive myoclonus and tardive Tourettism [2].

TS has been commonly attributed to hypersensitivity or upregulation of dopamine receptors, particularly the D2 subtype, following chronic blockade. A more recent hypothesis relates to synaptic plasticity. Synapses have the ability to increase or decrease the effectiveness of transmission through distinct mechanisms mediated by increases in intracellular calcium. It has been proposed that hyper-sensitization of D2 receptors and a direct drug action on NMDA receptors could provoke maladaptive plasticity in cortex and basal ganglia. This would lead to reduced selectivity of motor commands and aberrant motor learning [18].

The present experiments used TMS methods to probe the excitability of motor cortex circuits in order to obtain further evidence of the pathophysiological changes in TS. In physiological terms, reduced selectivity of motor commands equates to less control over access of excitatory inputs to corticospinal neurons. Given that a TMS pulse activates synaptic inputs to corticospinal neurons, we predicted that if this were the case, a TMS pulse would generate a larger response in TS than in healthy participants. Reduced selectivity could also result from changes in the excitability of inhibitory circuits. We therefore evaluated these by measuring the duration of the contralateral and ipsilateral silent periods which follow the muscle twitch evoked by TMS, and which are thought to be due in part to activation of GABAergic connections within motor cortex [22]. We did not measure plasticity directly since some of the medications such as amantadine (which has actions on NMDA receptors) or propranolol (Nitsche et al., 2004) that the TS patients were taking at the present time may interact directly with these assessments. 


\section{Methods}

Twenty two patients with drug induced Tardive Syndromes (12 males and 8 females, mean age $41.15 \pm 16.8$ years; range, 21-62 years) as defined according to the diagnostic and statistical manual of mental disorders (DSM V) [1], were recruited from the outpatient clinic of Aswan University Hospital. Education Depending on the previous antipsychotic drugs that they received they were classified into 3 groups: 5 patients had received $1^{\text {st }}$ generation antipsychotic (Haloperidol 50 mg/ 2-4 weeks or clopexol Depo 200 $\mathrm{mg} / 3-4$ weeks), 4 patients had received $2^{\text {nd }}$ generation antipsychotic (respiredone or aripeprazole 4-6 mg/day) and 13 patients had received both $1^{\text {st }}+2^{\text {nd }}$ generation antipsychotic drugs. The previous duration of treatment ranged from to 12 - 30 months. All patients stopped antipsychotic treatment after developing tardive syndromes. The average duration of TS was $18.3 \pm$ 30.8 months ranging from 1 month to 120 months. At the time of study, patients were receiving a variety of medications including amantadine, benzotropine, propranolol, biperiden "anticholinergics", but with little effect on TS. The duration of current medical treatment was $6.06 \pm 8.8$ months ranging from 2 weeks to 36 months. Exclusion criteria: patients who had history of metabolic disorders (Diabetes Millets, renal or liver impairment) or had history of seizure, severe dementia or any neurological disorders were excluded. Patients with magnetic or any other implanted device or patients with a history of, intracranial lesion on neuroimaging were also excluded.

None of the patients suffered from any other clinically relevant disorders. Each patient was assessed with the abnormal involuntary movement scale (AIMS) [7]. The AIMS test has a total of twelve items rating involuntary movements of various areas of the patient's body. These items are rated on a five-point scale of severity from $0-4$. The scale is rated from 0 (none), 1 (minimal), 2 (mild), 3 (moderate), 4 (severe). Two of the 12 items refer to dental care. The remaining 10 items refer to body movements themselves. The mean patients' AIMS score was $12.4 \pm 2.9$ ranging from 5 to 17 points. 
Previously diagnosed psychiatric disorders (according to DSM V) were: 13 patients had schizophrenia, 9 had mood disorders. Tardive syndromes included: tardive dyskinesia (Oro-Buccal-lingual) in 10 patients, and tardive tremors, bradykinesia and rigidity in 12 patients. Details of demographic data of the patients are illustrated in table 1.

Twenty age- and sex-matched healthy volunteers (12 males and 8 females; mean age, $40.8 \pm 19.8$ years; range, 20-69 years) represented the control population for assessment of cortical excitability. Controls were asked not to take drugs that affect motor cortex excitability (dopaminergic, tranquillizer, antidepressant, or antiepileptic) for at least one week before the study as well as the same exclusion criteria of the patients. Education levels were the same in patients (mean $10.5 \mathrm{yrs}$ ) and controls (10.3 years).

The study was approved by the Institutional Ethical Committee of Aswan University Hospital, and subjects gave their informed consent according to the Declaration of Helsinki.

\section{Experimental Setup and Design}

Subjects sat in a comfortable chair. Electromyographic (EMG) recordings (Nihon Kohden 9400, Japan) from the first dorsal interosseous muscle of right hand were acquired with silver-silver chloride surface electrodes, using a muscle belly-tendon set-up, using a 3-cm-diameter ground electrode placed on the wrist. The EMG parameters included a bandpass of 20 to $1000 \mathrm{~Hz}$ and a recording time window of 200 ms. TMS was performed with a $90-\mathrm{mm}$ figureof eight coil connected to Magstim (UK) super rapid magnetic stimulator. RMT, AMT, I/O, cSP and iSP were evaluated as previously reported by Khedr et al $[8,9,10,11]$. Any trials in which there was detectable pre-stimulus EMG activity were discarded from the analysis on the basis that this indicated that the participants were not completely relaxed. Motor thresholds were determined after localization of the motor "hot spot" for the first dorsal interosseous muscle in each hemisphere. The EMG signals were monitored and recorded for $20 \mathrm{~ms}$ before stimulation. Resting motor threshold (RMT) was measured at complete rest; active motor threshold (AMT), while subjects made a mild contraction of approximately $10 \%$ maximum. Both RMT and AMT 
were expressed as a percentage of the maximal stimulator output (equal to $100 \%)$.

Input-output curve was evaluated at rest by increasing the intensity of stimulation in steps of $10 \%$ from $110 \%$ to $150 \%$ of RMT. At each intensity, five trials were collected, with intertrial intervals of 5 seconds, and averaged.

The contralateral cortical silent period (CSP) of each hemisphere was evoked with stimuli of $130 \%$ RMT during isometric $50 \%$ maximum voluntary contraction of the contralateral first dorsal interosseous muscle. Contraction started $5 \mathrm{~s}$ before TMS. Ten stimuli were delivered not closer than once every $15 \mathrm{~s}$ to avoid fatigue. The EMG traces were rectified and averaged. The length of the cortical silent period (ms) was determined visually from the end of the MEP to the recurrence of at least $50 \%$ of EMG background activity. Ipsilateral silent period (iSP) was assessed in the same way, except that the subject contracted the ipsilateral first dorsal interosseous muscle, and the stimulation intensity was $150 \%$ RMT. If RMT was above $65 \%$ of maximum stimulator output, then maximum intensity was used. The onset and the offset of iSP were defined as the points where the EMG trace fell persistently below and where it returned persistently to the base line. The transcallosal inhibition duration was calculated as the time of offset of transcallosal inhibition minus the onset of transcallosal inhibition (ms).

\section{Statistical Analysis}

One- or two-way analysis of variance (SPSS version 16) was used to compare measures between patients and controls. Means \pm standard deviation (SD) were used to represent data. The level of significance was set at $P<0.05$. A two factor repeated measures analysis of variance (ANOVA) with "groups" (patients versus control) and "intensity" as main factors was conducted for the $1 / O$ and CSP curves. When necessary, a GreenhouseGeisser correction was applied to correct for non-sphericity. Post hoc unpaired $t$ tests were carried out for specific comparisons of data from the two groups. Non-parametric Spearman correlation between the AIMS score and different parameters of cortical excitability was also performed. The subgroup analysis (medication, previous psychiatric condition and type of involuntary movement) used one or two way ANOVA to compare measures of thresholds, $\mathrm{I} / \mathrm{O}$ curve, and silent periods between groups. 


\section{Results}

Motor Thresholds

There were no significant differences in either RMT or AMT between patients and controls (table 2).

\section{Input-output (I/O) Curve}

A two-way repeated measures analysis of variance with main factors of "TMS intensity" (110, 120, 130,140, and 150\% of RMT) and "group" (patients and controls) showed a significant intensity $X$ group interaction $(F=3.6, d f=1.6$ (65), and $P=0.03$ ). This was attributable to significantly higher amplitudes of MEP at 130,140 , and $150 \%$ of RMT (Table 2 and Fig. 1a).

\section{CSP at different TMS intensities}

A two-way repeated measures analysis of variance with main factors of "TMS intensity" (110, 120,130,140, and 150\% of RMT) and "group" (patients and controls) showed no significant group $X$ intensity interaction $(F=0.89, d f=$ 2.6 (104), and $P=0.43$ ). However; there was a significant main effect of group, meaning that at all intensities studied, the cSP was longer in the patients than the controls specially at stimulus intensities $(110,120,130$, and $140 \%$ of rMT (Table 2 and Figure 1b).

iSP

The iSP was significantly longer in patients in comparison to controls $(p=$ 0.0001) (table 2 and figure 1c).

\section{Correlations}

The clinical severity was assessed for each patient using the AIMS score. There was no significant correlation between the score and any of the parameters of cortical excitability.

Sub-group analysis (medication, previous psychiatric condition and type of involuntary movement) Table 3A, B and C 
There were no significant differences between neurophysiological results (rMT, aMT, I/O curve, iSP and CSP) in any of the subgroup analysis (Table $3)$.

\section{Discussion}

The main finding of this study was that despite similar thresholds, MEPs were larger in patients than the healthy control group. There was also a significant prolongation of both the iSP and CSP (at 110, 120, 130, $140 \%$ of rMT). The results are opposite to those described in early Sydenham chorea reported by Khedr et al.[8].

\section{Motor thresholds}

These TMS measures probe a range of physiological functions in motor cortex. MT is the minimum TMS intensity required to evoke an EMG response and is thought to reflect axonal membrane excitability, since it is increased following medication with voltage-gated sodium channel blockers [23], but unaffected by drugs which modulate GABAergic or glutamatergic transmission[23, 24]. The fact that MT was normal in patients suggests that TS is not due to a long term effect of antipsychotic drugs on the excitability of axonal membranes.

\section{Input-Output relationship}

The $1 / O$ curve measures how the amplitude of the MEP varies with TMS intensity. Because the MEP is produced by activity in corticospinal fibers that excite spinal motoneurons, the $1 / O$ curve gives an indication of how easily a TMS pulse can evoke corticospinal activity. Interestingly, TMS itself does not stimulate corticospinal neurons directly; instead it activates neurons that have synaptic inputs to corticospinal neurons. Thus the $\mathrm{I} / \mathrm{O}$ curve gives information about the excitability of inputs to corticospinal output neurons. As we argued in the Introduction it has been proposed that TS results from a disorder of synaptic plasticity that reduces the selectivity of motor commands. The fact that we observed increased $\mathrm{I} / \mathrm{O}$ curves in TS is compatible with this idea since it would predict increased access of synaptic inputs to corticospinal output. 
Note that the increased $1 / O$ curve is unlikely to be a direct effect of antipsychotic drugs since all patients had stopped treatment few weeks (23weeks) before assessment. It therefore seems likely that antipsychotic treatment in some individuals causes a long term change in synaptic mechanisms that does not reverse after stopping treatment. The patients' current medications are not known to have effects on I/O slope [25]. The changes are also unlikely to be a direct result of long term changes in the excitability of dopamine receptors in TS since dopaminergic drugs have been reported to have no effect on corticospinal excitability, at least in single dose studies in healthy adults.

\section{Silent Periods}

The cSP and iSP are both thought to involve activity in GABAb receptormediated systems [17, 20]. Interestingly, the cSP duration at lower stimulus intensities ( $110 \%$ and $120 \%$ of MT) could reflect activation of GABAa receptors, whereas the longer CSP at higher stimulus intensities (140\% of MT) may reflect the activation of GABAb receptors [15]. Thus the tendency for both CSP and iSP to be longer in patients might suggest that these GABAergic connections are more excitable in patients.

However, several groups have noted that the duration of the cSP depends on the amplitude of the MEP $[14,19]$. In the present case, patients have a larger MEP for a given intensity of stimulation than the control group. Thus it could be that the longer cSP, is a secondary consequence of the larger MEPs. Examination of the I/O slope and the cSP-intensity relationship suggest that this is a likely possibility. If we assume that the EMG activity in patients and controls is comparable (i.e. that the compound muscle action potential to supramaximal peripheral nerve stimulation is the same in each group) then the MEP evoked at $150 \%$ intensity in controls is approximately equal in size to the MEP evoked by $130 \%$ intensity in patients. Looking at the cSP-intensity relationship shows that the duration of the cSP at $130 \%$, is $140 \mathrm{~ms}$ in patients which is similar to that measured in controls at $150 \%$, consistent with the notion that the changes in CSP are secondary to differences in MEP amplitude in patients and controls. 
There is no data on the relationship between iSP duration and MEP amplitude. However, the iSP is produced by activation of pyramidal neurons in layer III of cortex. If these have an increased excitability similar to that of the corticospinal neurons of layer $\mathrm{V}$ that produce the MEP, then this may account for the longer iSP.

Another possibility is that the changes in CSP and iSP are related to the underlying psychiatric condition of the patients. However, in many cases these are the opposite to what we observed although the literature suggests a complex interaction between pathology and drug treatment. For example, Wobrock et al. [21] reported that patients with limited exposure to drugs have longer cSP, whereas Liu et al. [13] found treatment resistant patients to have shorter CSP. The effect of drug treatment is also unclear. Clozapine and quietapine increase cSP [16, 12], whereas the atypical neuroleptic olanzapine and the classical neuroleptic haloperidol do not alter CSP duration in healthy subjects [4]. Note that since we did not measure the maximum compound muscle action potential the possibilities of drug induced changes at the level of neuromuscular junction or spinal motoneuron cannot be excluded.

\section{Comparison with other movement disorders}

There is a large literature on responses to TMS in patients with movement disorders. We will focus the discussion here on corticospinal excitability since this was the major abnormality that we observed in TS. In general excitability has been reported to be reduced in Parkinson's disease (needs a review citing here, like Edwards \& Rothwell 2013), whereas in other pathological hyperkinesias such as Huntington's disease or Sydenham's chorea [8], it is reduced (Schippling et al, 2009; Khedr et al) or normal (in Huntington's disease: Philpott et al Behav Brain Res. 2016 Jan 1;296:311-317).Dystonia is usually reported to have normal excitability (REF). In the hyperkinetic disorders, reduced excitability is sometimes seen as a possible compensatory mechanism that tries to reduce the over-excitability of basal ganglia output. Since this does not occur in drug induced disorders, (even though there has been plenty of time for long-term changes to happen), it points to a rather 
different pathophysiology. The "natural" conditions might have more specific pathology in basal ganglia, whereas the drug-induced deficit could be much more widespread.

To the best of our knowledge, this is the first study to describe abnormalities of cortical excitability using TMS in subjects with tardive syndrome. These preliminary findings indicate that corticospinal output is hyperexcitable in individuals with TS. If so, then one potential avenue for treatment might be to induce Long Term Depression (LTD) using forms of rTMS or tDCS to reduce excitability. Further work on the physiological characterization of the TS population is needed with increased sample size and classification into different subtypes of TS.

\section{Limitation of the study:}

More research is necessary to identify which medications have the least association with TD and movement disorders

$M$ response and the possibilities of drug induced changes at the level of neuromuscular junction or spinal motoneuron is added in the discussion and as a limitation of the study

\section{PATHOPHYSIOLOGY}

The pathophysiology of TD lacks a universally accepted theory and mechanism. Several hypotheses have been proposed that include prolonged blockade of postsynaptic dopamine receptors leading to dopamine receptor supersensitivity, gamma-aminobutyric acid (GABA) depletion,

cholinergic deficiency, oxidative stress, altered synaptic plasticity, neurotoxicity, and defective neuroadaptive signaling. With regard to the dopamine hypothesis, chronic dopamine

blockade can result in upregulation of dopamine receptor responsiveness that can result in an exaggerated response of the postsynaptic dopamine receptors to dopamine.

3Evidence also indicates the involvement of GABA in TD.

Damage to GABAergic neurons by medications that affect

GABA functioning in the striatum, a brain region involved with oral musculature movements, could explain some of the hallmark symptoms of TD.34 Muscimol, a GABAmimetic agent, decreases abnormal movements in TD subjects. 36 Furthermore, evidence suggests a direct link between GABA and dopamine in that GABA neurons can directly inhibit dopamine neurons in discrete brain regions. 37 These data suggest a delicate balance between dopamine and GABA that, if interrupted, could result in TD.

\section{Conflict of interest statement}

\section{None}

\section{References}


[1]-American Psychiatric Association. Diagnostic and Statistical Manual of Mental Disorders. 5th ed Arlington, VA: American Psychiatric Association; 2013;. 712 p.

[2]-Bhidayasiri R, Boonyawairoj S. Spectrum of tardive syndromes: clinical recognition and management. Postgrad Med J. 2011; 87(1024):132-41.

[3]-Boroojerdi B ,Töpper R, Foltys H, Meincke U. Transcallosal inhibition and motor conduction studies in patients with schizophrenia using transcranial magnetic stimulation.Br J Psychiatry 1999; 175: 375-379.

[4]- Daskalakis ZJ, Christensen BK, Chen R, Fitzgerald PB, Zipursky RB, Kapur S. Effect of antipsychotics on cortical inhibition using transcranial magnetic stimulation.Psychopharmacology (Berl). 2003 Nov;170(3):255-62.

[5]- Di Lazzaro V, Oliviero A, Pilato F, Saturno E, Dileone M, Tonali PA. Motor cortex hyperexcitability to transcranial magnetic stimulation in Alzheimer's disease: evidence of impaired glutamatergic neurotransmission?. Ann Neurol 2003; 53(6): 824; author reply 824-5.

[6]- Fernandez HH, Friedman $\mathrm{JH}$. Classification and treatment of tardive syndromes. Neurologist 2003; 9: 16-27.

[7]- Guy W. ECDEU Assessment Manual for Psychopharmacology: Revised (DHEW publication number ADM 76-338). Rockville, MD, US Department of Health, Education and Welfare, Public Health Service, Alcohol, Drug Abuse and Mental Health Administration, NIMH Psychopharmacology Research Branch, Division of Extramural Research Programs, 1976; 534-7.

[8] Khedr EM, Ahmed MA, Ali AM, Badry R, Rothwell JC. Changes in motor cortical excitability in patients with Sydenham's chorea. Mov Disord. 2015 ;30(2):259-62.

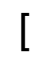

[9]- Khedr EM, Abo-Elfetoh N, Elbeh KA, Baky AA, Gamal RM, El Hammady $D$, et al. Transcranial magnetic stimulation identifies cortical excitability changes in monosymptomatic nocturnal enuresis. Neurophysiol Clin. 2015;45(2):151-8. 
[10]- Khedr EM, Gabra RH, Noaman M, Abo Elfetoh N, Farghaly HS. Cortical excitability in tramadol dependent patients: A transcranial magnetic stimulation study. Drug Alcohol Depend 2016, 1;169:110-116.

[11]- Khedr EM, Elbeh KA, Elserogy Y, Khalifa HE, Ahmed MA, Hafez MH, et al. Motor cortical excitability in obsessive-compulsive disorder: Transcranial magnetic stimulation study. Neurophysiol Clin. 2016;46(2):135-43.

[12]- Langguth B, Eichhammer P, Spranz C, Landgrebe M, Frick U, Sand $P$, et al. Modulation of human motor cortex excitability by quetiapine.Psychopharmacol ogy (Berl). 2008 196(4):623-629.

[13]- Liu SK, Fitzgerald PB, Daigle M, Chen R, Daskalakis ZJ. The relationship between cortical inhibition, antipsychotic treatment, and the symptoms of schizophrenia. Biol. Psychiatry 2009; 65: 503-509.

[14]- Orth M, Rothwell JC. The cortical silent period: intrinsic variability and relation to the waveform of the transcranial magnetic stimulation pulse.

Clin Neurophysiol 2004; 115(5): 1076-1082.

[15]- Paulus W, Classen J, Cohen LG, Large CH, Di Lazzaro V, Nitsche M, et al . State of the art: pharmacologic effects on cortical excitability measures tested by transcranial magnetic stimulation. Brain Stimul 2008; 1: 151-163.

[16]-Radhu N, de Jesus DR, Ravindran LN, Zanjani A, Fitzgerald PB, Daskalakis ZJ. A meta-analysis of cortical inhibition and excitability using transcranial magnetic stimulation in psychiatric disorders. Clin Neurophysiol 2013; 124 (7): 1309-20.

[17]- Siebner HR, Dressnandt J, AuerC, Conrad B. Continuous intrathecal baclofen infusions induced a marked increase of the transcranially evoked silent period in a patient with generalized dystonia. Muscle Nerve 1998; 21 : 1209-1212.

[18]- Teo JT, Edwards MJ, Bhatia K. Tardive dyskinesia is caused by maladaptive synaptic plasticity: a hypothesis. Mov Disord 2012; 27(10): 12051215.

[19]- Werhahn KJ, Behrang-Nia M, Bott MC, Klimpe S. Does the recruitment of excitation and inhibition in the motor cortex differ? J ClinNeurophysiol 2007 ;24(5):419-23.

[20]- Werhahn KJ, Kunesch E, Noachtar S, Benecke R, Classen J. Differential effects on motorcortical inhibition induced by blockade of GABA uptake in humans. J Physiol 1999; 517: 591—597.

[21]- Wobrock T, Schneider-Axmann T, Retz W, Rösler M, Kadovic D, Falkai $P$, et al.Motor circuit abnormalities in first-episode schizophrenia assessed 
with transcranial magnetic stimulation. Pharmacopsychiatry 2009 ;42(5):194201.

[22]- Ziemann U, Netz J, Szelenyi A, Homberg V. Spinal and supraspinal mechanisms contribute to the silent period in the contracting soleus muscle after transcranial magnetic stimulation of human motor cortex. Neurosci Lett 1993; 156: 167-171.

[23]-Ziemann U, Lönnecker S, Steinhoff BJ, Paulus W. Effects of antiepileptic drugs on motor cortex excitability in humans: a transcranial magnetic stimulation study. Ann. Neurol 1996; 40: 367-378.

[24]-Ziemann U, Chen R, Cohen LG, Hallett M. Dextromethorphan decreases the excitability of the human motor cortex. Neurology 1998;51(5):1320-4.

[25]- Ziemann U, Reis J, Schwenkreis P, Rosanova M, Strafella A, Badawy

R,et al. TMS and drugs revisited 2014. Clin Neurophysiol 2015 ;126(10):1847-68.

16. Correll CU, Leucht S, Kane JM. Lower risk for tardive dyskinesia associated with secondgeneration antipsychotics: a systematic review of 1-year studies. Am J Psychiatry. 2004 Mar;161(3):414-425. doi: 10.1176/appi.ajp. 161.3.414.

17. Gebhardt S, Hartling F, Hanke M, et al. Prevalence of “ movement disorders in adolescent patients with schizophrenia and in relationship to predominantly atypical antipsychotic treatment. Eur Child Adolesc Psychiatry. 2006 Oct;15(7):371-382. doi: 10.1007/s00787-0060544-5.

18. Yassa R, Jones BD. Complications of tardive dyskinesia: a review. Psychosomatics. 1985 Apr;26(4):305-313. doi: 10. 1016/S0033-3182(85)72863-0.

19. Kim J, Macmaster E, Schwartz TL. Tardive dyskinesia in patients treated with atypical antipsychotics: case series and brief review of etiologic and treatment considerations. Drugs Context. 2014 Apr 9;3:212259. doi: 10.7573/dic. 212259.

\section{Figure Legends}

Figure 1a: Amplitude of MEP in input/output curve $(\mu \mathrm{V})$ at different intensities $(110,120,130$, $140,150 \%$ of resting motor threshold). There were significantly higher amplitudes of in patients compared to controls (at 110,120,130,140\%) and a statistically significant significant interaction between the curves $(p=0.03)$. Figure $1 \mathbf{b}$ : The duration of the contralateral silent period at different intensities $(110,120,130,140,150 \%$ of resting motor 
threshold). There was significantly longer CSP duration in patients at stimulus intensities 110 , 120,130 , and $140 \%$ RMT.

Figure 2: Ipsilateral silent period duration (iSP). The iSP duration was longer in patients than controls $(P=0.0001)$.

Table 1: Demographic and clinical data of studied groups

\begin{tabular}{|l|l|}
\hline Demographic and clinical parameters & $\mathrm{N}=22$, Mean $\pm \mathrm{SD}$ \\
\hline Age (Years) & $41.45 \pm 14.6$ \\
\hline Sex male/female & $15 / 7$ \\
\hline Duration of tardive syndromes (months) & $14.9 \pm 19.8$ \\
\hline Duration of treatment of tardive syndromes (months) & $6.7 \pm 8.6$ \\
\hline Background psychiatric illness Mood disorder/schizophrenia & $9 / 13$ \\
\hline Offending antipsychotic & $\begin{array}{l}5 \text { patients received } 1^{\text {st }} \text { generation antipsychotic }, 4 \\
\text { patients received } 2^{\text {nd }} \text { generation antipsychotic and } 13 \\
\text { patients received both } 1^{\text {st }} \text { and } 2^{\text {nd }} \text { generation } \\
\text { antipsychotic drugs. }\end{array}$ \\
\hline Current treatment with little effect on Tardive Syndromes (TS) & $\begin{array}{l}\text { Amantadine, benzotropine and Biperiden, propranolol, } \\
\text { sodium valproate }\end{array}$ \\
\hline Types of Tardive Syndromes & $\begin{array}{l}\text { Tardive dyskinesia: classical oro-buccal-lingual (OBL) } \\
\text { dyskinesia and to choreic movements in other body } \\
\text { parts (10 patients) } \\
\text { Tardive tremors: Manifests with kinetic, postural and } \\
\text { resting tremor, usually with high amplitude, frequency of } \\
3-5 \mathrm{~Hz} \text { in the absence of parkinsonian (12 patients) } \\
\text { signs. }\end{array}$ \\
\hline Abnormal involuntary movement scale (AIMS) & $12.7 \pm 3.3$ \\
\hline Overall severity & $2.7 \pm 0.7$ \\
\hline Incapacitation & $2.4 \pm 0.7$ \\
\hline Awareness & $2.5 \pm 0.9$ \\
\hline
\end{tabular}


Table (2): Cortical excitability parameters of TS versus controls

\begin{tabular}{|l|l|l|l|l|}
\hline & $\begin{array}{l}\text { Patients } \\
\mathrm{N}=22 \\
\text { Mean } \pm \text { SD }\end{array}$ & $\begin{array}{l}\text { Control } \\
\mathrm{N}=20 \\
\text { Mean } \pm \mathrm{SD}\end{array}$ & $\begin{array}{l}\mathrm{P} \\
\text { value }\end{array}$ & $\begin{array}{l}\text { Repeated } \\
\text { measure } \\
\text { analysis (Time } \\
\mathrm{x} \text { groups) }\end{array}$ \\
\hline Age (years) & $41.5 \pm 14.6$ & $40.8 \pm 19.8$ & 0.91 & \\
\hline Resting motor threshold (RMT) & $42.2 \pm 5.8$ & $42.6 \pm 6.2$ & 0.83 & \\
\hline active motor threshold(AMT) & $36.0 \pm 5.4$ & $34.9 \pm 5.7$ & 0.52 & \\
\hline Amplitude of MEP in input/output curve $(\mu \mathrm{V})$ & & & & \\
$110 \%$ & $172.1 \pm 172.2$ & $143.9 \pm 106.9$ & 0.43 & $\mathrm{~F}=3.6, \mathrm{df}=$ \\
$120 \%$ & $532.9 \pm 771.3$ & $288.9 \pm 190.7$ & 0.17 & $1.6(65)$, and \\
$130 \%$ & $824.9 \pm 957.1$ & $326.5 \pm 230.9$ & 0.02 & $\mathrm{P}=0.03$ \\
$140 \%$ & $1143.9 \pm 1327.8$ & $526.8 \pm 335.7$ & 0.02 & \\
$150 \%$ & $1445.6 \pm 1250.7$ & $843.3 \pm 545.1$ & 0.05 & \\
\hline Cortical silent period duration in output curve $(\mathrm{ms})$ & & & & \\
$110 \%$ & $94.7 \pm 31.7$ & $67.9 \pm 25.3$ & 0.004 & \\
$120 \%$ & $127.7 \pm 46.4$ & $91.9 \pm 40.7$ & 0.01 & $\mathrm{~F}=0.89, \mathrm{df}=$ \\
$130 \%$ & $153.4 \pm 55.0$ & $104.9 \pm 41.5$ & 0.002 & $2.6(104)$, and \\
$140 \%$ & $170.1 \pm 56.4$ & $135.9 \pm 34.1$ & 0.02 & $\mathrm{P}=0.43$ \\
$150 \%$ & $181.8 \pm 72.3$ & $147.6 \pm 43.1$ & 0.06 & \\
\hline Transcallosal inhibition duration $(\mathrm{ms})$ & $34.8 \pm 8.6$ & $24.8 \pm 7.1$ & 0.0001 & \\
\hline
\end{tabular}


Table 3A: Sub-group analysis; type of antipsychotic in relation to physiological parameters

\begin{tabular}{|c|c|c|c|c|c|}
\hline $\begin{array}{r}\text { Parameters of } \\
\text { cortical } \\
\text { excitability }\end{array}$ & $\begin{array}{l}1^{\text {st }} \text { generation ( } 5 \\
\text { patients) }\end{array}$ & $\begin{array}{l}2^{\text {nd }} \text { generation (4 } \\
\text { patients) }\end{array}$ & $\begin{array}{l}1^{\text {st }}+2^{\text {nd }} \\
\text { generation (13 } \\
\text { patients) }\end{array}$ & $\begin{array}{l}\text { P value } \\
\text { One way } \\
\text { ANOVA } \\
\text { between the } \\
\text { three groups }\end{array}$ & $\begin{array}{l}\text { P value } \\
\text { two way } \\
\text { ANOVA } \\
\text { Intensity X } \\
\text { groups }\end{array}$ \\
\hline rMT & $39.8 \pm 6.4$ & $43.3 \pm 2.2$ & $42.8 \pm 6.4$ & 0.59 & \\
\hline $\mathrm{aMT}$ & $33.8 \pm 7.5$ & $37.00 \pm 2.2$ & $36.5 \pm 5.3$ & 0.60 & \\
\hline $\begin{array}{l}\text { I/O curve }(\mu \mathrm{V}) \\
110 \% \\
120 \% \\
130 \% \\
140 \% \\
150 \%\end{array}$ & $\begin{array}{l}123.9 \pm 63.4 \\
306.1 \pm 278.3 \\
524.2 \pm 492.9 \\
924 . \pm 1164.9 \\
1257.8 \pm 1267.6\end{array}$ & $\begin{array}{l}94.4 \pm 45.2 \\
134.4 \pm 111.8 \\
359.9 \pm 423.5 \\
564.2 \pm 649.9 \\
987.7 \pm 828.7\end{array}$ & $\begin{array}{l}214.6 \pm 140.3 \\
742.9 \pm 943.4 \\
1083.7 \pm 1137.9 \\
1406.9 \pm 1223.7 \\
1658.8 \pm 1533.6\end{array}$ & $\begin{array}{l}0.14 \\
0.30 \\
0.31 \\
0.40 \\
0.60\end{array}$ & $\begin{array}{l}F=0.75, \\
d f=3.0(29), \\
P=0.72\end{array}$ \\
\hline $\begin{array}{l}\operatorname{cSP}(\mathrm{ms}) \\
110 \%\end{array}$ & $115.1 \pm 35.6$ & $76.5 \pm 37.2$ & $92.5 \pm 26.5$ & 0.18 & \\
\hline
\end{tabular}




\begin{tabular}{|l|l|l|l|l|l|}
\hline $120 \%$ & $143.7 \pm 58.4$ & $96.7 \pm 45.7$ & $131.2 \pm 45.1$ & 0.30 & $\begin{array}{l}F=2.1, \\
\mathrm{df}=3.9(37), \\
130 \%\end{array}$ \\
$140 \%$ & $148.7 \pm 49.0$ & $104.7 \pm 49.7$ & $170.2 \pm 52.7$ & 0.10 & $\mathrm{P}=0.09$ \\
$150 \%$ & $163.4 \pm 47.8$ & $126.6 \pm 47.8$ & $186.1 \pm 57.4$ & 0.14 & \\
& $177.5 \pm 50.0$ & $123.5 \pm 76.6$ & $201.6 \pm 72.7$ & 0.16 & \\
\hline iSP & $37.3 \pm 10.6$ & $26.1 \pm 9.6$ & $36.5 \pm 6.2$ & 0.07 & \\
\hline
\end{tabular}

rMT; resting motor threshold, aMT; active motor threshold, CSP; cortical silent period, iSP; ipsilateral silent period, I/O; Input/Output curve

Table 3B: Sub-group analysis; background psychiatric illness in relation to physiological parameters

\begin{tabular}{|l|l|l|l|l|}
\hline & $\begin{array}{l}\text { Schizophrenia } \\
\text { (13 patients) }\end{array}$ & $\begin{array}{l}\text { Mood } \\
\text { disorders }(9 \\
\text { patients })\end{array}$ & $\begin{array}{l}\text { One way } \\
\text { ANOVA } \\
\text { between 3 } \\
\text { groups }\end{array}$ & $\begin{array}{l}\text { Two way } \\
\text { ANOVA } \\
\text { Intensity } x \\
\text { groups groups }\end{array}$ \\
\hline rMT & $42.9 \pm 3.4$ & $41.7 \pm 7.1$ & 0.60 & \\
\hline aMT & $36.2 \pm 3.6$ & $35.8 \pm 6.5$ & 0.86 & F=0.49, \\
If $=1.7(34)$, \\
P=0.58
\end{tabular}




\begin{tabular}{|l|l|l|l|l|}
\hline $130 \%$ & $119.9 \pm 51.9$ & $133.1 \pm 43.5$ & 0.287 & \\
$140 \%$ & $148.0 \pm 59.7$ & $151.8 \pm 53.7$ & 0.124 & \\
& $159.5 \pm 52.1$ & $177.4 \pm 60.1$ & 0.079 & \\
& $164.3 \pm 68.3$ & $194.0 \pm 75.1$ & 0.022 & \\
\hline iSP & $34.0 \pm 10.7$ & $35.3 \pm 7.3$ & 0.158 & \\
\hline
\end{tabular}

rMT; resting motor threshold, aMT; active motor threshold, CSP; cortical silent period, iSP; ipsilateral silent period, I/O; Input/Output curve

Table 3C: Sub-group analysis type of Tardive symptoms) in relation to physiological parameters

\begin{tabular}{|c|c|c|c|c|}
\hline & $\begin{array}{l}\text { Tardive dyskinesia } \\
\text { (10 patients) }\end{array}$ & $\begin{array}{r}\text { Tardive tremors } \\
\text { (12 patients) }\end{array}$ & $\begin{array}{l}\text { One way } \\
\text { ANOVA } \\
\text { between } 3 \\
\text { groups }\end{array}$ & $\begin{array}{l}\text { Two way } \\
\text { ANOVA } \\
\text { (time X3 } \\
\text { groups) }\end{array}$ \\
\hline rMT & $40.9 \pm 4.4$ & $43.3 \pm 6.8$ & 0.33 & \\
\hline aMT & $35.2 \pm 5.6$ & $36.6 \pm 5.6$ & 0.53 & \\
\hline $\begin{array}{l}\text { I/O curve } \\
110 \% \\
120 \% \\
130 \% \\
140 \% \\
150 \%\end{array}$ & $\begin{array}{l}139.8 \pm 67.6 \\
269.8 \pm 249.8 \\
485.1 \pm 664.2 \\
687.4 \pm 772.9 \\
951.6 \pm 962.9\end{array}$ & $\begin{array}{l}199.1 \pm 152.9 \\
752.4 \pm 984.6 \\
1108.2 \pm 1093.4 \\
1524.4 \pm 1277.5 \\
1857.3 \pm 1522.5\end{array}$ & $\begin{array}{l}0.24 \\
0.12 \\
0.17 \\
0.07 \\
0.10\end{array}$ & $\begin{array}{l}F=2.1 \\
d f=1.6(32), \\
P=0.14\end{array}$ \\
\hline $\begin{array}{l}\text { CSP } \\
110 \%\end{array}$ & $88.9 \pm 40.0$ & $99.5 \pm 23.6$ & 0.47 & $\begin{array}{l}F=0.69 \\
d f=1.7(33)\end{array}$ \\
\hline
\end{tabular}




\begin{tabular}{|l|l|l|l|l|}
\hline $120 \%$ & $111.2 \pm 50.4$ & $141.5 \pm 39.8$ & 0.14 & $P=0.48$ \\
$130 \%$ & $140.0 \pm 57.5$ & $164.5 \pm 52.7$ & 0.31 & \\
$140 \%$ & $150.1 \pm 59.3$ & $186.7 \pm 50.2$ & 0.13 & \\
$150 \%$ & $171.6 \pm 85.1$ & $190.5 \pm 62.3$ & 0.56 & \\
\hline iSP & $34.1 \pm 11.1$ & $35.3 \pm 6.4$ & 0.76 & \\
\hline
\end{tabular}

rMT; resting motor threshold, aMT; I/O; input-output curve; active motor threshold, cSP; contralateral silent period, iSP; Ipsilateral silent period 

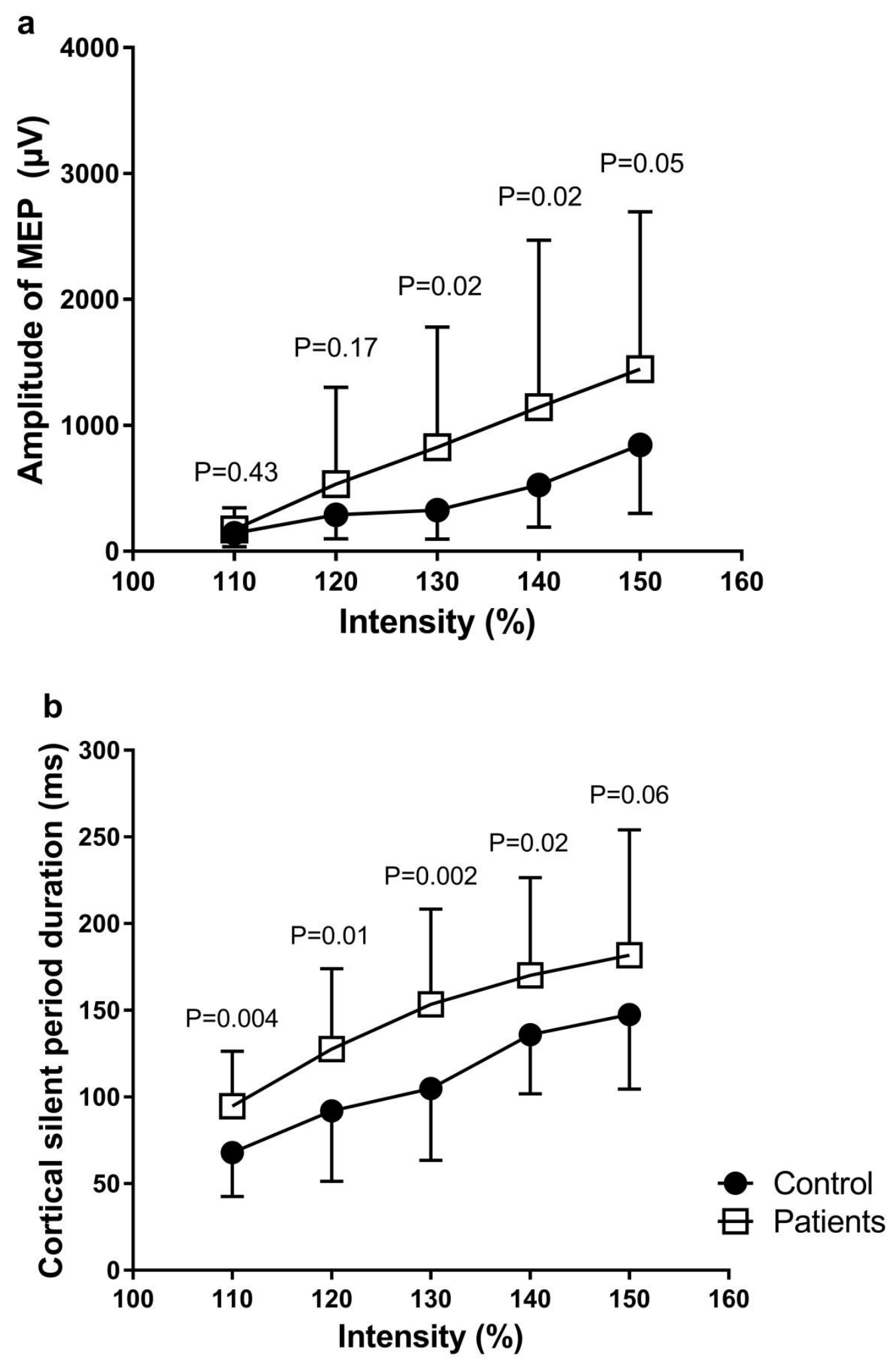

Figure 1 


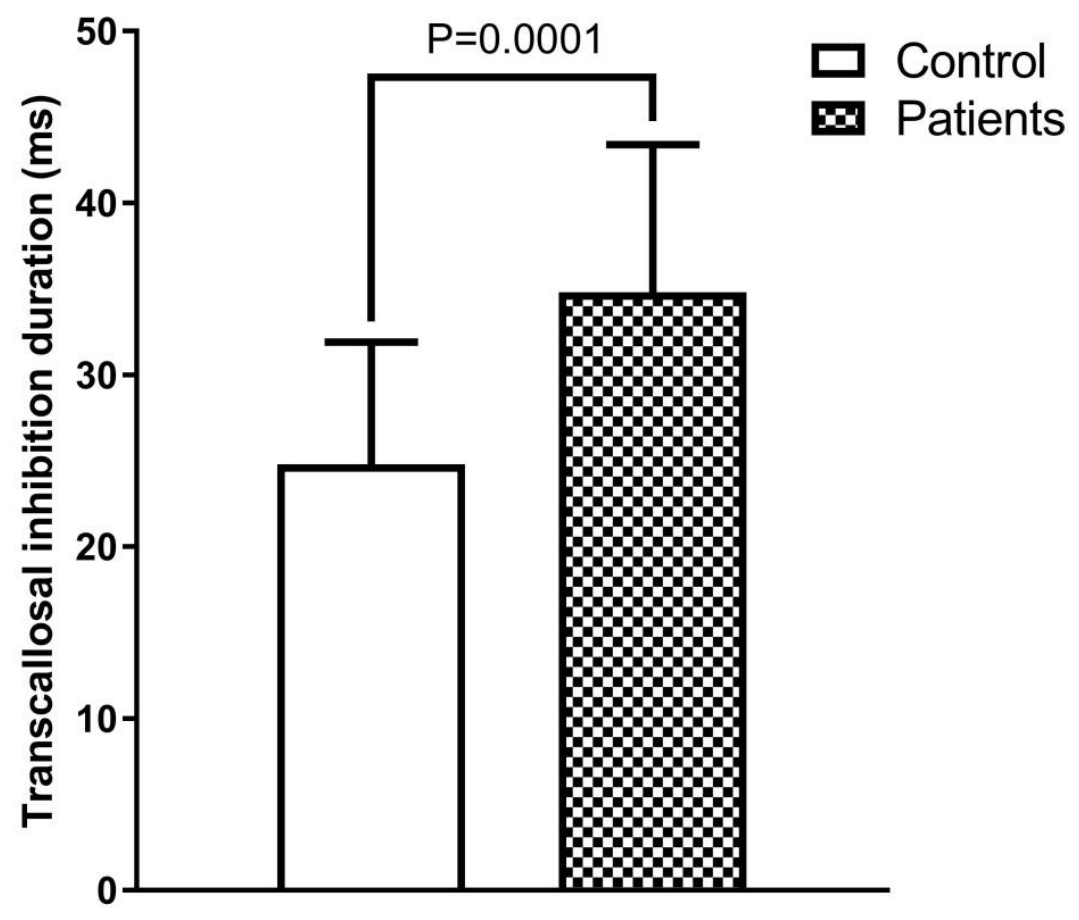

Figure 2 